\title{
El 'hispanismo' de Pedro Henríquez Ureña y Federico de Onís en Estados Unidos ${ }^{1}$
}

The ‘hispanicism’m of Pedro Henríguez Ureña and Federico de Onís in the United States

\author{
William Marín-Osorio*
}

Resumen: Se presenta una aproximación a la trayectoria de dos insignes intelectuales, el dominicano Pedro Henríquez Ureña y el español Federico de Onís, quienes contribuyeron a despertar el interés por el hispanismo en varias universidades de Estados Unidos y Latinoamérica. Se hace énfasis en su labor docente y de investigación, y en las relaciones que ambos sostuvieron con filólogos, filósofos, escritores e historiadores de la cultura como Ramón Menéndez Pidal, Marcelino Menéndez Pelayo, Miguel de Unamuno, José Ortega y Gasset, Américo Castro, Alfonso Reyes, José Vasconcelos, Gabriela Mistral, Dámaso Alonso y Amado Alonso. Finalmente, se da cuenta de algunas de sus más importantes contribuciones a los estudios sobre la literatura y la lengua españolas.

Palabras clave: español; cultura ibérica; cultura latinoamericana; lengua; literatura; filología; Estados Unidos; España; República Dominicana

Abstract: An overview of the trajectories of two noteworthy intellectuals is presented. Dominican Pedro Henríquez Ureña and Spanish Federico de Onís contributed to awaken interest in hispanism in a number of American and Latin American universities. Their teaching and research endeavors are emphasized, as well their relations with philologists, philosophers, writers and historians of culture such as Ramón Menéndez Pidal, Marcelino Menéndez Pelayo, Miguel de Unamuno, José Ortega y Gasset, Américo Castro, Alfonso Reyes, José Vasconcelos, Gabriela Mistral, Dámaso Alonso and Amado Alonso are stressed. Finally, it gives account of some of their most important contributions to studies on Spanish literature and the Spanish language.

Keywords: Spanish; Iberian culture; Latin American culture; language; literature; philology; United States of America; Spain; Dominican Republic

* Universidad Tecnológica de Pereira,

1 Artículo resultado de los proyectos de investigación con códigos 4-16-8, 4-16-9 y E1-18-1, inscritos en la Vicerrectoría de Investigaciones, Innovación y Extensión de la Universidad Tecnológica de Pereira (UTP), Colombia. Para Laura, Luciana, Patricia y Christian Daniel, quienes iluminan con su presencia el camino de mi vida. A Juan Carlos Mercado, Carlos Aguasaco, Yrene Santos y Carlos Velásquez, maestros y amigos de la Universidad de Nueva York (CUNY), Estados Unidos. A The Americas Poetry Festival of New York, International Conference on the Historical Links between Spain and North America y a la Division of Interdisciplinary Studies de The City College of New York (CUNY). A Ramona Hernández, directora del Dominican Studies Institute (CUNY). A Gustavo Bombini, maestro e investigador de la Universidad de Buenos Aires (UBA), Argentina, la Universidad Nacional de La Plata (UNLP), Argentina, y la Universidad Nacional de San Martín (UNSAM), Argentina. A Melchora Romanos, directora del Instituto de Filología y Literaturas Hispánicas "Dr. Amado Alonso", de la Facultad de Filosofía y Letras de la UBA. A Miguel D. Mena, pensador de las utopías de América con su editorial Cielonaranja, la colección Archivos y sus diferentes bibliotecas sobre literatura dominicana y del Caribe. 


\section{A MANERA DE PÓRTICO}

El presente ensayo gira en torno a Pedro Henríquez Ureña y Federico de Onís, y la manera en la cual estos intelectuales, unidos por la misma lengua e intereses culturales, representaron y proyectaron a España e Hispanoamérica en Estados Unidos, donde ejercieron la docencia, realizaron investigación y publicaron artículos, fomentando el interés por el estudio de la literatura y la lengua españolas en el mundo anglosajón.

¿Por qué son importantes estas figuras? ¿Por qué volvemos en pleno siglo XXI, a más de cien años de la publicación de sus primeras obras, a estos dos escritores? Si hacemos una historia del ensayo hispanoamericano, encontraremos que ambos, con aciertos y desaciertos en sus interpretaciones y búsquedas, fueron sendos fundadores de una forma de pensar y dueños de un singular estilo en la palabra y en la vida. De Pedro Henríquez Ureña, Borges dijo, en su famoso prólogo a la Obra crítica (edición de Emma Susana Speratti Piñero) - a propósito de la semblanza del dominicano, a quien llamó 'maestro de América'-: "Al nombre de Pedro [...] vincúlase también el nombre de América. Su destino preparó de algún modo esta vinculación [...] Alguna vez tuvo que oponer las dos Américas, la sajona y la hispánica, al viejo mundo; otras, las repúblicas americanas y España, a la República anglosajona del Norte" (2001: VIII). Es indudable que la unidad ibérica de la cultura hispánica, ideal de Miguel de Unamuno, encontró en Federico de Onís, y en su deseo de establecer lazos perdurables y duraderos entre España e Hispanoamérica, su más importante representante en América.

En la Universidad de Minnesota, Henríquez Ureña permaneció en calidad de Professorial lecturer de 1916 a 1921, contratado para enseñar literatura y lengua españolas; allí obtuvo en 1917 el título de Master of Arts con la tesis The Irregular Stanza in the Spanish Poetry of the XVIth and XVIIth Centuries. En mayo de 1918 presentó en español su tesis La versificación irregular en la poesía castellana en el Departamento de Lenguas Romances para optar al grado de Doctor of Philosophy. El texto fue aceptado por el Centro de Estudios Históricos de Madrid para su publicación en 1920 con prólogo de Ramón Menéndez Pidal. El documento original, mecanografiado y con anotaciones de puño y letra del intelectual dominicano, se conserva aún en la biblioteca principal y en los archivos bibliográficos y digitales de la Universidad de Minnesota (Henríquez Ureña, 1918). La tesis contiene ideas muy originales en torno al acento y la métrica españolas, con argumentos que le permiten al lector de nuestro tiempo acercarse a uno de los intereses del humanista. ${ }^{2}$

Otro centro académico donde la lengua y la literatura españolas se estudiaron con interés fue la Universidad de Columbia, recinto que acogió a Federico de Onís en 1916 en representación de la Junta para la Ampliación de Estudios e Investigaciones Científicas (JAE) ${ }^{3}$ para ayudar a organizar el Departamento de Español. Onís procedía del

2 En palabras de Henríquez Ureña: "La versificación castellana se considera, generalmente, como versificación silábica, al igual que la italiana o la francesa. En verdad, su fundamento primario es el hecho de que las sílabas castellanas son isócronas y [no cabe] distinguir largas y breves entre ellas, al menos para la métrica. De ahí se deriva el isosilabismo, es decir, el hecho [frecuente en todas las lenguas romances] de que cada tipo de verso tenga número fijo de sílabas, y el principio del isosilabismo se combina con el de los acentos: uno, el final, como obligatorio; otros, los interiores, como necesarios o como voluntarios, según la longitud del renglón [...] De todos modos, la versificación que encontramos en la poesía popular y vulgar de Castilla será, cuando se aparte de los moldes silábicos, más irregular que la galaico-portuguesa conocida, tanto en los versos como en las estrofas; y todo nos obliga a pensar que el camino de transmisión del occidente al centro fue popular y no culto: la escuela trovadoresca castellana se dedicaba entonces, con ardor de neófito, a la versificación silábica, y son muy contados, como se verá, los poetas cortesanos que hacen ensayos rítmicos" (1918: 1, 14 15) [las cursivas son mías y corresponden a los fragmentos escritos a mano por el autor en el original].

3 La JAE nació en 1907 en España, en el marco de la Institución Libre de Enseñanza (ILE) (1876-1936). De 1907 a 1939, el organismo creó centros de investigación y puso en contacto a la intelectualidad española con sus pares del resto de Europa y de otros continentes. Su propósito era divulgar los estudios de lengua y literatura españolas por medio de un programa de becas para estudiar en el extranjero y un intercambio de profesores y alumnos. En 1920, la JAE inauguró en Nueva York el Instituto de las Españas. 
Centro de Estudios Históricos de Madrid y había sido alumno de Miguel de Unamuno, a quien admiraba desde muy joven, pero sin dejar de reconocer el magisterio de José Ortega y Gasset y de Marcelino Menéndez Pelayo. A este último lo conoció a través de la carta de recomendación que le envió Unamuno para que Onís realizara sus estudios doctorales en Madrid. Onís se doctoró bajo la dirección de Ramón Menéndez Pidal con la tesis Contribución al estudio del dialecto leonés. Examen filológico de algunos documentos de la Catedral de Salamanca (1909), que se encuentra alojada en el repositorio documental de la Universidad de Salamanca. En este texto, el autor hace una disertación sobre aspectos formales de la lengua en algunos documentos históricos de dicha ciudad. ${ }^{4}$

Pedro Henríquez Ureña y Federico de Onís tuvieron una estrecha relación con el fundador de la escuela filológica española, Ramón Menéndez Pidal, miembro destacado de la llamada generación del 98, grupo de intelectuales y escritores españoles que sufrieron la crisis espiritual generada en España por la guerra hispano-estadounidense de 1898, en la que la península perdió sus últimas colonias de ultramar: Cuba, Puerto Rico y Filipinas.

En la Universidad de Columbia, donde permaneció hasta su retiro en 1954, Federico de Onís que emigró a Estados Unidos en 1916 después de regentar las cátedras de Lengua y Literatura en las Universidades de Oviedo y Salamanca - fundó los estudios de Letras Hispánicas y en 1920

4 En la tesis de Onís, leemos: "El leonés moderno no presenta casos de apócope de la $e$ final, a la usanza del antiguo castellano, detrás de ciertas terminaciones, de lo cual se encuentran también ejemplos en los antiguos textos leoneses, aunque mucho más restringidamente que en los castellanos. En cambio muestra el habla moderna de algunas regiones la conservación de la e tras $d$ romance y la inserción paradójica de una e detrás de $r$ y $l$ en ciertas palabras. Del estudio de los documentos antiguos, Staaff, que se detiene en este punto, viene a deducir que el dialecto leonés 'no revela ni siquiera en la región oriental tendencia al apócope'. Lo cual no obsta para que se encuentre un corto número de formas apocopadas, pertenecientes sobre todo a los documentos que Staaff coloca en su primer grupo, es decir, el más oriental" (Onís, 1909: 16-17). aceptó la dirección del Instituto de las Españas —organismo que contó con el respaldo de la Universidad de Columbia y el apoyo financiero de Archer Milton Huntington (1870-1955), creador de la Hispanic Society of America y gran divulgador de la cultura española en Estados Unidos-. En 1940, el Instituto de las Españas fue rebautizado como Hispanic Institute.

En 1920, Federico de Onís publicó el texto El español en los Estados Unidos, ensayo que fue la lección inaugural del inicio académico 19201921 de la Universidad de Salamanca. En él hace referencia a su experiencia como español en el país americano y revela la existencia de un movimiento intelectual en la Universidad de Columbia que expresaba una gran admiración por España —nación que había 'descubierto' América-, un interés por las huellas que dejó en el territorio de su país, especialmente en Florida, y una inclinación por conocer su cultura, lengua e historia. Onís también explica que ese entusiasmo se consolidó en una pléyade de intelectuales y hombres de acción cuyo origen no era español $\mathrm{y}$, sin embargo, fueron los encargados de difundir la cultura de la península en Estados Unidos: los hispanistas.

Los nombres de Washington Irving, Longfellow, Prescott, Ticknor, Lowell, Howells, vendrán enseguida a la imaginación de todos. No ha estado nunca difundido el estudio del español como lo está ahora; pero no dejaba de estudiarse en las universidades y colegios más importantes, llegando a producirse una brillante escuela de hispanistas que han consagrado sus vidas al estudio de nuestra lengua, literatura e historia. Antes de que el interés por ellas se hiciese general y popular como lo es ahora, se habían dado a conocer y habían mantenido sin interrupción el interés por nuestras cosas un buen número de especialistas e investigadores tales como Ford, Pietsch, Shepherd, Lang, Schevill, Northup, Carolina Bourland, Rennert, Marden, Buchanan, Espinosa, Crawford, 
Hills, Fitz-Gerald, Morley, Olmstead, Bransby, Wagner, Umphrey, Keniston, House, Chandler, De Haan y tantos otros cuyo nombre y cuya labor son bien conocidos entre cuantos en el mundo se dedican a estudios filológicos y literarios. Toda esta tradición españolista de los Estados Unidos vino a culminar en la creación de la Hispanic Society of America, cuya biblioteca y museo constituyen el monumento más grandioso que se ha levantado a España en el extranjero. La inteligencia, el amor y la devoción de un solo hombre, Archer M. Huntington, nombre que debe sonar siempre en labios españoles con gratitud y admiración, han hecho el milagro de reconstituir en el seno de esta ciudad de Nueva York una síntesis espléndida de lo más alto de nuestra civilización, que estará aquí ante los ojos de los norteamericanos como una enseñanza perpetua de lo que nuestro espíritu es y de lo que hemos hecho por el mundo (Onís, 1920: 14-15).

El insigne intelectual tuvo contacto a lo largo de toda su vida con la Universidad de Salamanca. En 1905 se graduó como Licenciado en Artes en el Colegio Mayor de San Bartolomé; allí fortaleció su amistad intelectual con Unamuno. A partir de 1910, estableció un vínculo estrecho y duradero con José Ortega y Gasset, por cuyas ideas estéticas y políticas sentía gran admiración y afinidad, especialmente en cuanto a sus reflexiones sobre 'la europeización de España o la españolización de Europa', que le valieron una fuerte polémica con Unamuno. Federico de Onís desarrolló en su patria una brillante carrera como estudioso de la lengua española y su literatura, y trabajó como bibliotecario en la sección de archivos de la Universidad de Oviedo, donde regentó la cátedra de Lengua y Literatura Españolas en 1911. Luego se trasladó a la Universidad de Salamanca.

Onís nunca perdió sus vínculos académicos y afectivos con España; testimonio de ello fueron los permanentes viajes a su país natal, circunstancia que quedó plasmada en la colección
España en América. Estudios, ensayos y discursos sobre temas españoles e hispanoamericanos, publicada por la Universidad de Puerto Rico ${ }^{5}$ en 1955. Ya antes, las Canciones españolas (Spanish folk songs) (1931) habían sido editadas en el Instituto de las Españas por Emiliano de Torre. En su obra Ensayos sobre el sentido de la cultura española (1932) discutía la existencia de un Renacimiento español análogo, e incluso "superior al del resto de Europa”. Para Onís, si España era la tradición, a Hispanoamérica le correspondía conservarla.

\section{Pedro Henríouez Ureña y su utopía intelectual}

Henríquez Ureña nació en el seno de una familia aristocrática el 29 de junio de 1884 en Santo Domingo, República Dominicana, y murió en Buenos Aires, Argentina, el 11 de mayo de 1946. Fue hijo de Salomé Ureña, recordada como una de las más importantes poetas de su país, y de Francisco Henríquez y Carvajal, escritor, médico y presidente interino en 1916. Su abuelo, Nicolás Ureña de Mendoza, había cultivado el costumbrismo y también ejerció la política.

En este ambiente creció el futuro autor de reconocidas y controvertidas obras que ya son parte de la cartografía intelectual latinoamericana, como Ensayos críticos (1905), Horas de estudio (1910), La versificación irregular en la poesía castellana (1918), En la orilla. Mi España

5 En 1925, Onís llegó a la Universidad de Puerto Rico por invitación del rector Thomas E. Benner. Allí desarrolló una importante labor académica en el campo de la investigación lingüística y literaria. En 1927 fundó el Departamento de Estudios Hispánicos y dirigió el Seminario de Estudios Hispánicos que hoy lleva su nombre. En 1928 creó la Revista de Estudios Hispánicos, que tuvo el apoyo del Centro de Estudios Históricos de Madrid, la Sociedad Cultural Española y la Universidad de Columbia, a donde regresó para continuar con su cátedra en 1931. En 1934, en Nueva York, dirigió la Revista Hispánica Moderna. Onís realizó una intensa labor en otros países de América. En Cuba, aceptó la dirección del Instituto de Estudios Hispánicos de la Universidad Central de las Villas (1957-1958); en 1947, dictó conferencias sobre el hispanismo en Colombia, Venezuela, Costa Rica, Guatemala, Ecuador, Panamá, Cuba, Perú, Argentina, Uruguay y Chile; entre 1942 y 1947 fue profesor invitado en la Universidad de Texas y en 1949 en la Universidad de Denver. 
(1922), La utopía de América (1925), Seis ensayos en busca de nuestra expresión (1928), Sobre el problema del andalucismo dialectal de América (1937), Para la historia de los indigenismos. Papa y batata. El enigma del ajé. Boniato. Caribe. Palabras antillanas (1938a), El español en México, los Estados Unidos y América Central (1938b), Plenitud de España. Estudios de historia de la cultura (1940a), El español en Santo Domingo (1940b), Historia cultural, historiografia y crítica literaria (1945) - la mayoría de estos textos compilados en Obra crítica (1960), La utopía de América (1978) y Obras completas (1980) - Literary Currents in Hispanic America (1945, compendio de sus reflexiones en la Charles Eliot Norton Lectures(1940-1941) de la Universidad de Harvard), Historia de la cultura en la América hispánica (1947, edición póstuma) y Las corrientes literarias en la América hispánica (1949, edición póstuma), de la colección Biblioteca Americana del Fondo de Cultura Económica (FCE).

Entre la copiosa bibliografía sobre Henríquez Ureña, hallamos la investigación de Alfredo Roggiano, autor de dos textos fundamentales para entender el periplo del escritor dominicano: Pedro Henríquez Ureña en los Estados Unidos (1961) y Pedro Henríquez Ureña en México (1989). Esta segunda obra da cuenta de la salida del joven escritor de Cuba hacia el puerto de Veracruz con su primer libro, Ensayos críticos (1905), publicado en La Habana, un compendio de sus reflexiones sobre Rubén Darío, José Enrique Rodó, Gabriele D’Annunzio, Óscar Wilde, George Bernard Shaw, la sociología de Eugenio María de Hostos, el modernismo en la poesía cubana, además de otros temas. Roggiano indaga, igualmente, en su primera estancia en Estados Unidos, experiencia que representó empezar a labrar su destino como intelectual y hombre de letras en un país extraño, de grandes edificios, con otra cultura e idioma.

Podemos señalar dos momentos clave en el itinerario de Henríquez Ureña por Estados Unidos.
Una primera etapa comienza en enero de 1901 y finaliza en 1904. En esa ocasión, acompañó a su padre en una misión diplomática, quien, representando los intereses de República Dominicana, buscaba la refinanciación de la deuda con los acreedores externos de su país.

En este viaje inicial a Nueva York, acompañaron a Pedro su hermano mayor Francisco Noel y, poco tiempo después, su hermano menor, Max. ${ }^{6}$

Henríquez Ureña llegó a Estados Unidos con prejuicios antiamericanistas que habían nacido a raíz de sus lecturas del Ariel de José Enrique Rodó y de la obra poética de Rubén Darío. Sin embargo, estas ideas desaparecieron poco tiempo después, cuando se integró a la sociedad anglosajona con todos sus espectáculos y manifestaciones artísticas e intelectuales. El dominicano dejó constancia de ello en sus Memorias, publicadas en su primera edición por la Academia Argentina de Letras (1989), y posteriormente, por el FCE (2000). Durante su estadía de aproximadamente tres años en Nueva York, asistió a conferencias en universidades, visitó el Museo Metropolitano, la biblioteca de la Universidad de Columbia y la Biblioteca Astor —donde leyó a D’Annunzio, Georges Brandes, Máximo Gorki, Rudyard Kipling, a los clásicos griegos y la literatura nórdica—, frecuentó el Metropolitan Opera House -donde escuchó Las bodas de Fígaro, La flauta mágica, Romeo y Julieta, Carmen, La Traviata, Aida, Otello, El oro del Rhin, entre otros clásicos de la música europea-, asistió a representaciones de las obras de William Shakespeare,

6 Leemos en Memorias. Diario. Notas de viaje: "En New York nos encontramos a varios dominicanos: al expresidente D. Alejandro Woz y Gil, hombre de inteligencia sutil, grande amigo de mi padre y mi primo Enrique; al Cónsul Leonte Vásquez, hermano del entonces vicepresidente Horacio [...] Con el fin de que cuanto antes aprendiéramos el inglés en toda forma (pues era poco lo que recordábamos de los cursos recibidos en el Liceo Dominicano) mi padre nos buscó una casa de huéspedes en el barrio de la Universidad de Columbia; y pronto nos instalamos en la casa de Mr. \& Mrs. Henry E. Fournier, 329 West 113th Street. El marido era hijo de francés, y hablaba el idioma; la señora era americana, y era mujer perspicaz y amable y conversadora, joven todavía; su conversación fue acaso nuestro mejor maestro de inglés" (Henríquez Ureña, 1989: 66). 
Henrik Ibsen, George Bernard Shaw, escribió artículos y su primer poema de carácter modernista, "Flores de otoño", ${ }^{7}$ publicado en el periódico El Ideal del Ateneo de la Juventud de la ciudad de Santo Domingo.

El modernismo fue el movimiento más estudiado por Henríquez Ureña. En Ensayos críticos —un libro típicamente modernista, al decir de Laura Febres-, analiza la figura de Rubén Darío y afirma: "su oda "A Roosevelt" es un himno casi indígena, es un reto de la América Española a la América Inglesa" (Henríquez Ureña, 1905: 102). En Las corrientes literarias en la América hispánica, fruto de sus conferencias leídas en inglés en la cátedra Charles Eliot Norton, dedica importantes reflexiones a revelar el significado de la actitud del modernismo frente a la política hispanoamericana. Para el dominicano, después de la independencia, la anarquía y un periodo de relativa estabilización social, surgió la paz del liberalismo económico. ${ }^{8}$ Con esto quería revelar las contradicciones existentes entre el intelectual de la época, su actitud crítica frente al mundo y el lenguaje, y las circunstancias sociales del ejercicio de la política en países inestables económicamente. En este contexto, nos recuerda el dominicano, el escritor forma parte de la división social del trabajo y, en consecuencia, "como la literatura no era en realidad una profesión sino una vocación, los hombres de letras se

7 He aquí sus primeros versos modernistas: "iCrisantemos, / crisantemos como el oro, / crisantemos cual la nieve, / desplegad vuestras corolas, /las corolas como el sol de mediodía, / las corolas como el mármol inmortal. / En el cielo sobre el fondo gris y opaco / brilla el sol lánguidamente, sin fulgores, / y su lumbre desmayada cual de pálido crepúsculo, / es oscuro polvo de oro. / Pardas nubes / en el cielo [...] / En tanto, los árboles sueñan. / Ensueños de vida, de savia bullente / de ramas profusas, / de frescas y vívidas flores/y de brisas cálidas / de fecundo riego / de aves amorosas, de cantos, de nidos. / Con la vida, en la lucha / cuán temprano sentí, lloré cuán presto. / Fue en tiempos lejanos, cuando florecía / la raza lejana bella y varonil. / A su ocaso descienden, dijiste, / las creencias un tiempo sagrado" (Henríquez Ureña, 1984).

8 A este respecto, señala: "Comenzó una división del trabajo. Los hombres de profesiones intelectuales trataron ahora de ceñirse a la tarea que habían elegido y abandonaron la política [...] El timón del Estado pasó a manos de quienes no eran sino políticos; nada se ganó con ello, antes al contrario" (Henríquez Ureña, 1949: 165). convirtieron en periodistas o en maestros, cuando no en ambas cosas" (Henríquez Ureña, 1949: 165)

Henríquez Ureña veía en los Estados Unidos la expresión vívida de la civilización moderna. Escribió entonces a su amigo Alfonso Reyes: "No es lo mismo vislumbrar la civilización a través de los libros que verla en los pueblos" (Reyes y Henríquez Ureña, 1986: 81). Después de este primer periodo en Nueva York, regresó a encontrarse con su padre en Cuba, país en el que se había exilado luego del golpe militar que sufrió el gobierno de República Dominicana, regentado por Juan Isidro Jiménez. En La Habana codirigió la revista Cuba Literaria. Con esta experiencia editorial y la publicación de artículos suyos en Santo Domingo, tomó la decisión de darse a conocer en el mundo de la crítica hispanoamericana con su primer libro, Ensayos críticos (1905), que referimos antes y que sin duda nació de sus lecturas en las bibliotecas de Nueva York.

Una segunda etapa (1914-1921) le permitió conocer varias ciudades de Estados Unidos. En 1914 viajó a Washington como corresponsal de El Heraldo de Cuba, diario en el que trabajaba en La Habana. Esta corresponsalía duró hasta 1915. Minerva Salado, poeta y ensayista cubana, publicó en la editorial Casa de las Américas Desde Washington (1975), una recopilación de los artículos que Henríquez Ureña enviaba a El Heraldo de Cuba desde la capital estadounidense y Nueva York, bajo el seudónimo E. P. Garduño. En 2004, el FCE de México, en la colección Biblioteca Americana que el dominicano proyectó en vida con Daniel Cosío Villegas, director de dicha institución, reeditó la obra con comentarios críticos y notas explicativas de Minerva Salado. Los textos incluidos constituyen un momento esencial para entender la posición del dominicano con respecto a los diferentes asuntos económicos y de política exterior derivados de las relaciones de su país con Estados Unidos. Se observa en muchos de sus artículos una crítica a las decisiones militares y económicas adoptadas por el país del norte 
frente al Caribe, advirtiendo su proceso de expansión e injerencia en los asuntos internos de los países latinoamericanos. ${ }^{9}$ Esta es, como podemos advertir, la etapa de formación política del académico, intelectual, profesor y futuro escritor, que será reconocido como uno de los más importantes críticos de América.

En Nueva York, de 1915 a 1916, trabajó para el semanario Las Novedades, en cuya imprenta publicó El nacimiento de Dionisos (1916), considerada el origen de la tradición del teatro dominicano. Esta obra es, ante todo, un ejercicio de acercamiento al mundo antiguo, una búsqueda y reconstrucción de la tragedia antes de Esquilo. La mitología será la fuente clásica de Henríquez Ureña, uno de los más importantes intereses en la vida espiritual del futuro ensayista. Una vez concluido este ciclo, ingresó a la Universidad de Minnesota, donde ejerció como profesor de Literatura y Lengua Españolas de 1916 a 1921. Además, publicó notas y artículos en diferentes periódicos locales. Durante esta estancia, estalló la crisis diplomática entre República Dominicana y Estados Unidos. Henríquez Ureña escribió a favor de los intereses de su nación y en contra de la ocupación estadounidense y el intervencionismo en

9 Leamos el siguiente artículo: "HACIENDA Y DIPLOMACIA. Acaba de salir de Washington, rumbo a la ciudad de Santo Domingo, Mr. James Mark Sullivan, Ministro de los Estados Unidos en la República Dominicana. Esta noticia, para muchas personas a quienes interesa la política de las Antillas, contrastará de modo discordante con los informes que se reciben de aquel país sobre las elecciones presidenciales [...] Pero los augurios de bienestar que traen consigo estas elecciones se enturbiarán, a los ojos de muchos dominicanos, con la noticia del regreso de Mr. Sullivan, que representa para ellos el peor aspecto de la injerencia de los Estados Unidos en los asuntos de la América española. Es generalmente conocida la especial situación, de vigilancia y dominio norteamericanos, a que están sometidas las aduanas de Santo Domingo desde el tratado o "convención" de 1907. Roosevelt se enorgullecía de esta obra de su gobierno. Los políticos republicanos la citaban como ejemplo de bienhechor influjo de los Estados Unidos en el mar Caribe, y le atribuían misteriosas virtudes pacificadoras. [...] desde que la administración demócrata nombró a Mr. Sullivan ministro en Santo Domingo, no falta quienes señalan la vigilancia de los Estados Unidos sobre la hacienda dominicana como un motivo para que las funciones del Ministro yankee se desnaturalicen, haciéndose más financieras que diplomáticas y convirtiéndose al fin en fuente de trastornos políticos" (Henríquez Ureña, 2004: 43-44). el Caribe. Sin embargo, por su condición de inmigrante y por fungir como profesor en una universidad de Estados Unidos, parte de sus críticos consideró su actitud como una traición a la oportunidad de trabajo ofrecida al dominicano en aquel momento histórico.

Nos recuerda Alfredo Roggiano que el primer artículo que publicó Henríquez Ureña sobre dicha situación de tensión política y económica se tituló "México and Pan-Americanism. The Dominican Republic- Another Test of Mr. Wilson sincerity" y apareció en el periódico The Minneapolis Journal el 26 septiembre de 1916 (1961: LXXII). En él subrayaba la injusticia de Estados Unidos hacia su patria. El dominicano acudió a dos asociaciones de la Universidad de Minnesota, compuestas por estudiantes y profesores, El Club Español y el Club de Relaciones Internacionales, donde se estudiaba y fomentaba el conocimiento de la situación social, política, económica y cultural de otras naciones. En ambas asociaciones, y con mayor énfasis en El Club Español, Henríquez Ureña ejercía una intensa actividad política a favor de los intereses de su patria, incluso hasta poco antes de viajar a México en 1921, invitado por Vasconcelos.

El escritor publicó el artículo titulado "El despojo de los pueblos débiles" en octubre de 1916, un reclamo a los países latinoamericanos por su falta de solidaridad con Santo Domingo a propósito de la invasión de Estados Unidos: "Salvar a la República Dominicana de la invasión 'yanqui' no conlleva gran notoriedad ni aplausos ruidosos [...] iTriste revelación del espíritu egoísta que impera en la familia de pueblos latinoamericanos!" (Henríquez Ureña, 1916: 294). En septiembre de 1919 pronunció el discurso "Memorándum sobre Santo Domingo" (Roggiano, 1961: 204), dirigido al senador Henry Cabot Lodge, en un intento por solucionar el conflicto con Estados Unidos.

Y iquién decide cuál país es civilizado y cuál no? Sólo la fuerza lo decide, hasta ahora: y si 
la fuerza hubiera de decidirlo, no tendríamos por qué quejarnos de Alemania: su teoría era ésa: como la nación más civilizada, debía civilizar al resto del mundo. No hay, pues, derecho para querer civilizar a otras naciones (Henríquez Ureña, en Roggiano, 1961: 204).

En el periodo comprendido entre el otoño de 1919 y el verano de 1920 se ausentó de la universidad para participar en las actividades investigativas del Centro de Estudios Históricos de Madrid. A su regreso de España, pronunció la conferencia "Relaciones de Estados Unidos y el Caribe", en el Club de Relaciones Internacionales de la Universidad de Minnesota, donde acusó a la presidencia de Woodrow Wilson (periodo 1913-1922) de implantar una visión de conquista en el Caribe, en su empeño de liderar, igualmente, una política exterior intervencionista en Latinoamérica, bajo el ideal panamericano que Henríquez Ureña veía traicionado por Estados Unidos. ${ }^{10}$

En 1921 viajó a México invitado por José Vasconcelos, secretario de Educación del presidente Álvaro Obregón, para colaborar en la reorganización del sistema educativo. A partir de este momento, Henríquez Ureña empezó una carrera intelectual en ese país: fundó el Ateneo de la Juventud, la Sociedad de Conferencias y consolidó un prestigio que luego lo llevó a Argentina. Ahí entró en contacto con Amado Alonso, quien dirigía el Instituto de Filología de la UBA, y también con otros intelectuales de la época, especialmente a través de la revista Sur, donde escribió al lado de Jorge Luis Borges, Victoria Ocampo, Silvina Ocampo, Adolfo Bioy Casares, Alfred Métraux, María Rosa Oliver, Eduardo Mallea, Leopoldo Marechal, Gabriela Mistral, entre otros destacados escritores.

Son innumerables los estudiosos de la obra del dominicano. Entre los académicos que

10 Y agregó: "Sin embargo, tal es el poder de la palabra, cuando representa ideas elevadas y las expresa bien, que conozco mexicanos que mantuvieron su fe en Wilson a pesar de todas sus contradicciones" (Henríquez Ureña, 1980: 44). destacan la labor intelectual del Henríquez Ureña crítico e hispanista, además del ya citado Borges, encontramos a Alfredo Roggiano, René Favaloro, Juan Jacobo de Lara, Soledad Álvarez, Miguel D. Mena, Néstor E. Rodríguez, Rafael Mondragón, Liliana Weinberg, Adolfo Castañón, Diony Durán, José Emilio Pacheco, Sergio Pitol, Emilio Rodríguez Demorizi, Enrique Zuleta Álvarez, José Luis Abellán, Ezequiel Martínez Estrada, Emilio Carilla, Raúl. H. Castagnino, José Carlos Mariátegui, Minerva Salado, Ana María Barrenechea, Beatriz Sarlo, Susana Zanetti, Noé Jitrik, Raúl Antelo, Daniel Link, Laura Febres, Emilia de Zuleta, Rafael Gutiérrez Girardot, Emma Susana Speratti Piñero y José Luis Martínez, si bien la lista es interminable. También están los críticos de su obra, especialmente los que consideran que hay vacíos en sus ensayos en el tratamiento de algunos temas, tales como el mundo prehispánico, el mulataje de la zona del Caribe, las manifestaciones culturales de lo luso-brasileño, su ausencia de una posición como intelectual representante de la alta cultura letrada hispanoamericana frente a Estados Unidos. Entre estos últimos sobresalen Juan Valdez, Claudio Maíz, Arcadio Díaz Quiñones, Fernando Valerio-Holguín y Fernando Degiovanni, quienes expresaron particulares visiones acerca de las posturas ideológicas de Henríquez Ureña y su influencia en los estudios sobre América Latina.

Henríquez Ureña fue un humanista en el sentido más cabal del término; frecuentó el helenismo inglés y era un entusiasta lector de los clásicos griegos. Un sector de la academia le reprocha que su formación intelectual tuviera este fondo y menospreciara, en consecuencia, la tradición de las letras latinoamericanas, los mundos prehispánico, antillano - Haití- y Brasil, campos de trabajo intelectual habitados de "estrategias escripturales de silencios", al decir de Fernando Valerio-Holguín, "con respecto a las culturas indígena y negra, como forma de lidiar con su condición de intelectual mulato poscolonial” (2011: 195). Para Arcadio Díaz Quiñones, 
"Henríquez Ureña se empeñó en ensanchar al máximo la continuidad, que para él estaba en la 'alta cultura' hispánica, aunque con la exclusión casi total de las culturas afrocaribeñas" (2008: 73). Por su parte, Juan Valdez (2008; 2010; 2015), aunque subraya la importancia de la obra del dominicano, también argumenta la ausencia de grandes temas no resueltos desde el punto de vista lingüístico, como la búsqueda de la identidad y el diálogo intercultural con Haití. Un ejemplo de ello es El español en Santo Domingo (1940b), en donde Henríquez Ureña expone su preocupación por la invasión, desde el lenguaje, de la vecina Haití a República Dominicana, preocupación que Valdez interpreta como 'ideología lingüística' de carácter racial y nacionalista. Otro tanto dirá Claudio Maíz. ${ }^{11}$

Fernando Degiovanni, ${ }^{12}$ por su parte, cuestiona la presencia de Henríquez Ureña en la Cátedra Charles Eliot Norton, espacio académico que había convocado a muchos intelectuales

11 En palabras del investigador: "Nuestro enfoque asume el Caribe como una figura ausente, y como un recorte en el atlas conceptual de Henríquez Ureña. He ahí nuestro interés. No es lo que escribió (poco en verdad) sobre el Caribe lo que nos llama la atención, entonces, sino la operación mediante la cual lo dejó fuera al confeccionar los bordes de la figura americana inscrita en su producción. Omitir la inestabilidad caribeña — dicho esto en un sentido amplio que va más allá de lo político — es, también, una manera de aludir a la identidad y al mestizaje que sí fueron sus preocupaciones centrales. En un cuadro conformado de ausencias, recortes y omisiones es donde intentamos formularnos las interrogantes antes indicadas. La preocupación por el orden y el idioma son dos enclaves firmes que a Henríquez Ureña le merman atracción por las áreas que están sumidas tanto en el caos político como, en cierto modo, el caos lingüístico. Con el fin de crear una imagen homogénea, unitaria, continua de Hispanoamérica, Henríquez Ureña compatibiliza en un mismo haz de significaciones la tradición 'nacional', la 'hispanoamericana' y la 'cosmopolita”' (Maíz, 2008: 13-14).

12 Degiovanni reflexiona: "El ofrecimiento de la titularidad de la cátedra Norton a un crítico dominicano proveniente de la Argentina, sin obra académica en inglés y cuya especialidad era marginal en el currículo universitario norteamericano tiene que haber sido visto como un gesto extraordinario en el contexto del ciclo de conferencias más prestigioso de los Estados Unidos. Desde la fundación de la cátedra Norton en 1925, sus ocupantes habían sido filólogos e historiadores de reputación internacional, en su mayoría procedentes de Inglaterra o de peso particularmente notorio en el mundo intelectual angloparlante. Nada de ese prestigio e influencia podía ofrecer Henríquez Ureña, profesor sin un cargo universitario titular en la Argentina, y con una actividad de prestigio internacional, como Ígor Stravinski y T. S. Eliot, por mencionar unos cuantos nombres, antes de la presentación de sus charlas tituladas "The Search for Expression: Literary and Artistic Creation in Spanish America" en 1940 en el Fogg Museum of Art. Henríquez Ureña fue el primer latinoamericano en hacer presencia allí; luego le siguieron, muchos años después, Jorge Luis Borges y Octavio Paz. Como señala Fernando Degiovanni, Henríquez Ureña, investido con la tradición de la revista Sur, dirigida por Victoria ocampo —-firmante del manifiesto Acción Argentina para promover la adhesión de este país a los aliados; que había asumido posiciones antifascistas y críticas frente al Eje-, y quien con experiencia académica e investigativa en el Instituto de Filología de la UBA, al lado de Amado Alonso, llegó a Harvard justo en el marco del inicio de la Segunda Guerra Mundial. El mundo estaba en crisis y América Latina se constituía

docente dispersa en institutos secundarios y terciarios. Pero la declaración de la Segunda Guerra en 1939 transformaría esas prioridades, debido a la necesidad de promover los intereses económicos y la legitimidad cultural de los Estados Unidos en el marco del vacío producido por las inversiones europeas en la región, sobre todo en Sudamérica. Apenas comenzadas las hostilidades alemanas, el Departamento de Estado inició una campaña de intervención directa en las universidades norteamericanas para asegurarse el apoyo ideológico y logístico de sus docentes de español. Las presiones llegarían incluso a los profesores peninsulares que, a raíz de la Guerra Civil Española, se habían incorporado a la academia norteamericana. Se esperaba no sólo que los hispanistas peninsulares actuaran como mediadores en la construcción de un latinoamericanismo pronorteamericano, sino que inclusive se dedicaran a enseñar e investigar cuestiones latinoamericanas. Américo Castro dejó testimonio de estas presiones y expectativas. Desde Princeton escribió una carta a Amado Alonso en la que le decía con evidente frustración: 'No hay semana que no venga aquí alguien, más o menos de Washington, a hablarme de cosas 'Latin American'. Les digo que qué diablos van a lograr allá [en América Latina] mientras no estén dispuestos a dar el salto'. Defensor de la centralidad de los estudios peninsulares en el currículum universitario norteamericano, Castro no sólo desaprobaba el nombre dado al campo, sino también tener que dedicarse a ese campo; pero al mismo tiempo, cuestionaba las estrategias de Estados Unidos en la región por tímidas e ineficaces. Según Castro, los funcionarios estatales que lo visitaban querían asegurarse el apoyo de "la opinión liberal hispanoamericana" y era consciente del rol que Washington esperaba que tuvieran los hispanistas en la implementación de la política del Buen Vecino. Por eso le hablaba a Alonso de lo que 'V., yo y mil más estamos haciendo para estrechar lazos"' (2015: 138-139). 
en un escenario perfecto para resolver los intereses económicos de Estados Unidos, situación que enfrentó estratégicamente Roosevelt con su política del 'buen vecino' (1928), que consistía en la no agresión militar para fomentar la inversión y la expansión económica en las tres Américas, promover la agenda cultural latinoamericana mediante conferencias, cátedras e intercambios académicos, fortalecer los lazos de cooperación y, en consecuencia, aumentar la presencia del país anglosajón en el continente.

Henríquez Ureña fue el baluarte de ese proceso de reconciliación con Estados Unidos, especialmente gracias a Literary Currents in Hispanic America (1945), sus conferencias publicadas por Harvard. Este documento, que prometía ser una exploración de las corrientes literarias en la América hispánica, revela paulatinamente la opinión política del intelectual dominicano, quien buscaba posicionarse en el hispanismo académico norteamericano y enviar un mensaje de orden social y lingüístico a su público anglosajón —especialmente, a partir de la presentación de Argentina y Brasil como epígonos de la voluntad de las élites criollas por mantener su estabilidad social y económica, algo poderosamente llamativo para Estados Unidos-. Henríquez Ureña sólo podía lograr esto mediante una exposición, en medio de lo literario, de la importancia que otorgaba a las élites criollas como promotoras del desarrollo, la construcción de una sociedad latinoamericana estable y la creación de un nuevo hombre. Sin duda, estas circunstancias históricas convenían a Estados Unidos, y tener en Harvard a un académico hispanoamericano que resolvía, desde el ámbito de la cultura, el asunto del 'buen vecino', fue una estrategia política para sus intereses económicos en el hemisferio. Como advierte Degiovanni, leer desde la cátedra Norton Las corrientes literarias en la América hispánica es asistir al fortalecimiento de un programa ideológico que, a partir de lo académico, propiciaba el acercamiento de los intereses financieros de Estados Unidos con América Latina, diseñando así, desde sus universidades, un latinoamericanismo pronorteamericano

Si bien es cierto que Henríquez Ureña tuvo una amplia formación literaria, filosófica e histórica, cuya erudición suscitó en Borges una profunda admiración, también lo es el hecho de que sus inquietudes intelectuales tuvieron como centro el estudio de las creaciones autóctonas originarias de nuestra América. Su ideal clásico, hispánico, de belleza, estuvo presente en muchos de sus libros, y no olvidó que la América hispánica también comprendía el área de Brasil. Basta leer sus lecciones En busca de nuestra expresión (1940), en donde hay amplios estudios sobre la arquitectura, la música y las letras luso-brasileñas como expresión de un mundo ordenado, unitario y homogéneo.

Es indudable que la presencia de su entrañable amigo Alfonso Reyes en Brasil (1930-1936), en calidad de embajador de México, y el encuentro en Buenos Aires con el arquitecto Julio Rinaldini, contribuyeron a formar en el dominicano una visión del mundo sobre Brasil como parte de la identidad y la historia de Latinoamérica. Con Rinaldini, Henríquez Ureña descubrió la pintura neoprehispánica en creadores de la talla de Pedro Figari, Cândido Portinari, las riquezas arquitectónicas de Mario José Buschiazzo, Martín Noel, Ángel Guido y al insigne restaurador de arte español Vicente Lampérez y Romea.

Estas influencias fueron esenciales para reconocer, en sus dos grandes obras finales, el legado cultural del mundo precolombino en el proceso de formación de la identidad latinoamericana. El marco de las conferencias de Henríquez Ureña en el Fogg Museum of Art estaba constituido por una exposición de obras de arte prehispánico, lo que le reveló al ensayista una sensibilidad hacia estas expresiones por parte de Estados Unidos, especialmente de sus académicos e intelectuales. Raúl Antelo (2009) señala, respaldado en sus investigaciones sobre la arquitectura y la pintura neoprehispánicas, que estas conferencias y el recinto donde tuvieron lugar fueron esenciales 
en la transformación del pensamiento y la sensibilidad de Henríquez Ureña sobre América Latina y su identidad. La exposición lo impresionó, por cuanto era algo que no había visto antes en el continente. El dominicano capitalizó estas experiencias para darle un giro prehispánico a sus ideas clásicas en Historia de la cultura en la América hispánica (1947) y para el desarrollo de sus Corrientes literarias en la América hispánica (1949), ambos libros de carácter póstumo.

En la revista Sur, donde Henríquez Ureña también escribía por la misma época — estaba allí desde su fundación y había contribuido con innumerables artículos sobre diversos temas culturales-, el célebre antropólogo y etnólogo Alfred Métraux había publicado una serie de seis ensayos entre 1931 y 1980. Métraux conoció el universo indígena latinoamericano y se constituyó en su más acérrimo defensor, criticando incluso a las élites criollas por desconocer su legado histórico y no defender sus contribuciones al desarrollo de la sociedad, lo que llamó 'el vacío del mundo indígena en el imaginario de América Latina'. Sin duda, Henríquez Ureña leyó en Sur los esfuerzos de Métraux por superar fronteras disciplinares, situar en primer orden los estudios antropológicos y divulgar estos conocimientos.

Las universidades estadounidenses, interesadas en lo prehispánico, empezaron a contratar a numerosos intelectuales, entre ellos Métraux y Henríquez Ureña, que expusieron diferentes concepciones modernas sobre Latinoamérica y sus raíces. Lo mismo sucedió con filólogos de la dimensión de Amado Alonso, contratado como catedrático e investigador en Harvard, y Federico de Onís, invitado por la Universidad de Columbia con el propósito de fundar el Departamento de Español y desarrollar actividades de intercambio cultural con España.

La amistad del dominicano con Borges, quien aún no recibía el reconocimiento que más tarde tuvo, fue esencial para su formación clásica. Henríquez Ureña fue el primero en advertir la universalidad del escritor argentino, tanto que corrigió algunos de sus textos y, junto con él, publicó la célebre Antología clásica de la literatura argentina (1937). Estados Unidos también vería en Borges a un alto representante de la cultura hispanoamericana. ${ }^{13}$

Como lo hiciera en su momento Estados Unidos al divulgar el mundo hispánico dentro de su medio académico, en Latinoamérica son diversas las universidades, cátedras —como la recién inaugurada "Cátedra Libre de Estudios Filológicos Latinoamericanos Pedro Henríquez Ureña", de la Facultad de Filosofía y Letras de la UBA-, revistas, archivos históricos — como el de la UNAM, el FCE, El Colegio de México, el Colegio Nacional "Rafael Hernández" de la Universidad Nacional de La Plata y la Biblioteca Nacional de Chile-, e intelectuales que luchan por conservar el legado del pensamiento de Pedro Henríquez Ureña —entre ellos, Liliana Weinberg (2014) y Rafael Mondragón (2016), que se han aplicado al estudio de la Biblioteca Americana que el dominicano proyectó entre 1945 y 1946 junto con Daniel Cosío Villegas; igualmente, Adolfo Castañón (2012) se ha dedicado a conservar y editar, con El Colegio de México, las cartas que cruzara con Alfonso Reyes entre 1914 y 1944-.

Un intelectual dominicano tiene en sus manos el proyecto de salvaguardar el legado de Pedro Henríquez Ureña. Nos referimos a Miguel D. Mena, sociólogo, editor, biógrafo e investigador literario, que ha estudiado con rigor su obra y ha publicado ediciones críticas de sus libros a

13 En 1961, Jorge Luis Borges visitó Estados Unidos a solicitud de la Universidad de Texas. En 1967, publicó con María Esther Zemborain de Torres Duggan una colección de ensayos titulada Introducción a la literatura norteamericana, y fue invitado por la Universidad de Harvard y su célebre cátedra Norton a dictar un curso de poesía titulado "This craft of verse" (Este oficio del verso), que fue editado por CalinAndrei Mihailescu y publicado por Harvard University Press en 2000. En 1969, la Universidad de Oklahoma organizó un congreso sobre su obra y en Nueva York se inició la publicación de sus textos en inglés. En 1971, las universidades de Columbia y Yale le otorgaron el doctorado honoris causa. Al año siguiente hizo lo mismo la Universidad de Michigan y se dio a conocer El oro de los tigres, un volumen de piezas disímiles que contiene una narración breve titulada "El sueño de Pedro Henríquez Ureña”, sobre las circunstancias de la muerte del dominicano. 
través de la Editorial Cielonaranja, que actualmente dirige. Mena también ha dado a conocer la obra de otros escritores dominicanos y caribeños, como el pedagogo puertorriqueño Eugenio María de Hostos y el poeta cubano José Martí, a quienes Henríquez Ureña conoció siendo un niño en su casa de Santo Domingo cuando su madre regentaba allí un instituto para señoritas, el primero dedicado a la formación de futuras maestras. La Editorial Cielonaranja tiene varias colecciones, entre las que encontramos la Biblioteca Pedro Henríquez Ureña, la Biblioteca de la literatura dominicana, la Biblioteca urbana, la Biblioteca cubana y Archivos. Esta última incluye diez tomos en torno a la figura de Pedro Henríquez Ureña, y ha convocado a grandes ensayistas hispanoamericanos, como Daniel Link, José Emilio Pacheco, Guillermo Toscano y García y Mónica Bernabé. La editorial publicó también catorce tomos con las obras completas del dominicano, textos clave que revelan al investigador de nuestro tiempo la historia de este intelectual y su tradición.

\section{Federico de Onís y su EXILIO}

Federico de Onís tuvo una historia personal singular. Nació en Salamanca, España, el 20 de diciembre de 1885 y se suicidó a la edad de 81 años, en San Juan de Puerto Rico, el 14 de octubre de 1966. Quienes han realizado la historiografía de su vida y obra, que no son pocos, incluso en el mundo anglosajón, hablan con admiración sobre su trabajo intelectual. Su vida académica fue extraordinaria, toda vez que resume la prodigiosa labor cultural de un hombre que se formó con figuras relevantes, como Unamuno, Menéndez Pidal y Ortega y Gasset, intelectuales de quienes heredó el ideario filológico, el carácter y la personalidad de hombre de acción, crítico de su España del alma.

A finales de los años veinte, establecido ya en Nueva York, Onís organizó una sección en el Instituto de las Españas dedicada a la cultura sefardí. Es importante subrayar que esta institución, fundada por él, no sólo dedicó sus esfuerzos a la divulgación de los estudios españoles, sino también a los sefardíes, portugueses e hispanoamericanos. ${ }^{14}$ Harriet, la esposa de Onís, quien conocía las lenguas portuguesa y española, contribuyó, igualmente, a divulgar y establecer un canon de la literatura latinoamericana en Estados Unidos con sus traducciones al inglés de muchos autores brasileños, entre ellos João Guimarães Rosa y Jorge Amado, además de escritores de habla hispana como Martín Luis Guzmán - El águila y la serpiente (The Eagle and the Serpent, 1930) es su primera traducción-. Alejo Carpentier, Alfonso Reyes, Fernando Ortiz y Ricardo Güiraldes. Harriet de Onís llegó a la Universidad de Columbia como estudiante y allí conoció al afamado filólogo español, quien ya había fundado el Instituto de las Españas. Su labor de traductora fue importante para el mundo latinoamericano, y en especial para el público de habla inglesa ansioso de conocer las obras de escritores provenientes de las culturas hispana y luso-brasileña, aunque este trabajo fue opacado por las actividades académicas de su esposo.

Menéndez Pidal, con quien Onís trabajó en el Centro de Estudios Históricos de Madrid junto con Américo Castro, estaba muy interesado en el romancero sefardí, entre otros innumerables trabajos de filología hispánica y del castellano medieval. En el siglo XV, con su expulsión por parte de los Reyes Católicos, los judíos sefardíes se desplazaron por toda Europa y América. Desde principios del siglo XX y hasta 1924, muchos de quienes habían encontrado residencia en Estados Unidos, procedentes de Marruecos, Turquía y los Balcanes, dieron pie en Nueva York a una generación de estudiosos del sefardí que realizó

14 Ramón Menéndez Pidal elogió en 1929 su labor cultural: "El Instituto de las Españas en los Estados Unidos está realizando una labor espiritual del más alto valor, ya que no sólo trabaja en pro de la cultura, sino también a favor de la aproximación y conocimiento mutuo de los pueblos de habla española, portuguesa e inglesa. Me complazco, pues, en alentar con mayor entusiasmo esa obra patriótica, altruista y de tan elevada idealidad" (1929: 117). 
doctorados en Columbia para proyectar su cultura en el mundo anglosajón e hispanoamericano. ${ }^{15}$

Este encuentro con la diversidad cultural de América en Nueva York, patrocinado por la JAE, le permitió a Onís no sólo crear el Departamento de Español en la Universidad de Columbia, sino también colaborar con varios centros universitarios de Estados Unidos en donde fue profesor visitante, e irradiar su esfera de acción hacia Hispanoamérica desde Puerto Rico, país que lo invitó a organizar en 1926 el Departamento de Estudios Hispánicos (Recinto de Río Piedras). Hoy funciona en la Universidad de Puerto Rico un seminario permanente con el nombre del filólogo español. Hay que subrayar que la fundación de los estudios hispánicos en esta isla se logró gracias al vínculo cultural entre Federico de Onís y los integrantes en ese momento del Centro de Estudios Históricos de Madrid, entre quienes se destacaban por sus aportes a la filología, la fonética y la literatura, Ramón Menéndez Pidal, Samuel Gili Gaya, Tomás Navarro Tomás, Amado Alonso y Dámaso Alonso.

En 1934, mientras ejercía la docencia y la investigación en Columbia, Federico de Onís publicó la Antología de la poesía española e hispanoamericana (1882-1923), una ambiciosa y controvertida obra que contribuyó a establecer desde la lengua española los vínculos entre España y la parte hispana de América. Más adelante, en 1961, Las Américas Publishing Company, en Nueva York, publicó nuevamente el texto, que constituye, sin duda, un paradigma para la comprensión del fenómeno del modernismo en ambas orillas del Atlántico. ${ }^{16}$ Curiosamente, al tiempo que se ahondaban en el siglo XIX

15 Para el lector interesado, invito a consultar Radio Sefarad (https:/www.radiosefarad.com/los-sefardies-hispanistas-dela-universidad-de-columbia/), especialmente la emisión del programa dedicado a la presencia de los judíos sefardíes en Nueva York, con la Dra. Paloma Díaz-Mas, investigadora del Consejo Superior de Investigaciones Científicas (CSIC) en el Instituto de Lengua, Literatura y Antropología de Madrid y estudiosa de los sefardíes hispanistas que trabajaron en la Universidad de Columbia en el periodo 1930-1950.

16 En su célebre ensayo titulado Sobre el concepto del modernismo, el crítico español señaló: "el modernismo es la forma las fracturas políticas entre España y sus excolonias americanas, se fortalecieron sus nexos lingüísticos y literarios mediante el modernismo, movimiento espiritual liderado como una auténtica revolución desde el lenguaje en la propuesta estética de Rubén Darío y que tuvo hondas repercusiones en la vida espiritual de España.

Es importante destacar también la labor de divulgación cultural de la Revista Hispánica Moderna, fundada en 1934 como expresión de las actividades del Boletín del Instituto de las Españas, en la Universidad de Columbia. Este órgano editorial fue dirigido por Federico de Onís y constituyó una extensión de la Revista de Filología Española, de Madrid.

En la bibliografía de Federico de Onís hallamos otros títulos fruto de sus incursiones en diferentes facetas filológicas, históricas y literarias: Disciplina y rebeldia (1915a), Ensayos sobre el sentido de la cultura española (1932), España en América (1955) y Anthologie de la poésie latino-américaine (1956). A él debemos también algunas ediciones críticas - El ingenioso hidalgo don Quijote de la Mancha, de Miguel de Cervantes (1957)—, prólogos —al Cancionero. Diario poético (1953) de Miguel de Unamuno, y a las Obras completas (1952) de Tomás Carrasquilla-, trabajos de crítica sobre la obra literaria de fray Luis de León (1915b), Jacinto Benavente (1923), El Martín Fierro y la poesía tradicional (1924), Luis Palés Matos (1959), y diversas antologías de poetas y prosistas que publicó hasta su muerte en 1966. Estas obras surgieron en un marco de interpretación del legado de Europa, especialmente España, en América, y de las relaciones culturales entre ambos continentes que, a juicio de Onís, tuvieron una gran importancia para definir lo que hicieron los americanos por sí mismos, lo original americano.

\footnotetext{
hispánica de la crisis universal de las letras y del espíritu, que inicia hacia 1885 la disolución del siglo XIX y que se había de manifestar en el arte, la ciencia, la religión, la política y gradualmente en los demás aspectos de la vida entera con todos los caracteres, por tanto, de un hondo cambio histórico cuyo proceso continúa hoy” (Onís, 1955: 176).
} 
España en Europa y en AmÉRICA

Los dos escritores que presentamos llevaron consigo el espíritu español e hispanoamericano en sus trabajos académicos, espíritu que se conoce como 'hispanismo', y que el Diccionario de la Real Academia Española define como una "afición al estudio de las lenguas, literaturas o culturas hispánicas" (RAE, 2020). Dicho término hace referencia, igualmente, al estudio en general de la cultura hispana tanto española como americana. Ambos intelectuales cuentan con el prestigio de haber ejercido la cátedra universitaria y la investigación literaria y filológica en Estados Unidos, contribuyendo con su trabajo a la consolidación del estudio de la lengua y la literatura españolas, y al gusto por lo hispanoamericano entre la sociedad de habla inglesa en un periodo de la historia estadounidense — principios y mediados del siglo XX- en que surgió un profundo interés por todo aquello proveniente del mundo de habla española — su idioma, letras y folclor-y, en general, por el legado de Cervantes a la cultura. La voz 'hispanismo' ha circulado en los medios académicos de muy diverso modo a partir de la formación del Diccionario de la RAE. ${ }^{17}$ Por su parte, el Diccionario de Autoridades $^{18}$ lo define como: "s. m. Modo de hablar particular y privativo de la Lengua Española [...] Latín. Hispanismus. PATON. Eloq. Prolog. Como usó Helenismos del Griego y del Hebreo, usa Hispanismos del Español. HoRTENS. Mar. f. 104.

17 El Diccionario es el producto de un sistemático proceso de reflexión y recopilación de información sobre la lengua que realizaron en el pasado humanistas como Antonio de Nebrija —que en 1492 publicó Gramática castellana (1992) y en 1517, Reglas de ortografía en la lengua castellana-, y Covarrubias — cuyo Tesoro de la lengua castellana o española (1611) se publicó con anterioridad al Diccionario de Autoridades (17261739) y fue concebido con una finalidad estrictamente etimológica-.

18 El Diccionario de Autoridades es el primer repertorio lexicográfico de la RAE, publicado entre 1726 y 1739 , que buscaba afianzar una norma culta basada en el uso que hacían de la lengua los mejores escritores, porque "han tratado la Lengua Española con la mayor propiedad y elegancia: conociéndose por ellos su buen juicio, claridad y proporción, con cuyas autoridades están afianzadas las voces".
Una fiesta que ha pocos años aun no era de guardar, como dice nuestro hispanismo" (2020: s/n).

Durante el siglo XVI, España fue el centro de un movimiento cultural sin precedentes que se irradió por toda Europa, ocupando un lugar destacado el interés por una imagen insólita del mundo procedente de otras manifestaciones culturales. Lo extraño y maravilloso, dos imaginarios que procedían de la España de la conquista de ultramar que traía consigo tierras desconocidas y un nuevo sentir, empezaban a hacer presencia en el orden social y cultural. Este aire de renovación condujo a la organización de un pensamiento innovador sobre el significado de España en Europa, y de su valor como unidad geográfica y lingüística frente al resto de las naciones. Para conocer esas realidades surgió la necesidad de aprender la lengua de la nueva potencia política y comercial del Renacimiento.

Quienes estaban atentos a estas transformaciones sociales, políticas, económicas y culturales eran los escritores, que al tomar la pluma realizaron una transformación radical en la forma de comprender el mundo hasta entonces conocido. Estos pensadores dieron forma, función y vitalidad, al decir de José Ortega y Gasset, a la lengua española que Europa deseaba conocer para entender esa realidad que se asomaba inesperadamente sobre su horizonte. El primero de estos pensadores fue Antonio de Nebrija, autor de la Gramática castellana (1492), considerada la primera gramática impresa en una lengua romance. A él le siguieron intelectuales como Juan de Valdés, autor del famoso Diálogo de la lengua (1736). El castellano fue así reconocido y hablado por ingleses, franceses e italianos, unificando a Europa alrededor de los mismos intereses comerciales, políticos y culturales.

Entre 1550 y 1670 se publicó una serie de diccionarios y gramáticas castellanas que permitieron la unidad lingüística de España, proyectos editoriales que fueron posibles gracias a la imprenta como nuevo fenómeno social y de masas. La publicación y distribución de estos 
textos propició el florecimiento de los estudios hispánicos de los que son herederas varias generaciones de filólogos, filósofos $y$, en general, hombres de letras, que empezaron a preocuparse por la cuestión de la unidad política y de la lengua de España frente a Europa.

Lo anterior tenía no sólo un fin académico, sino que se buscaba extender los dominios de la lengua. De allí que se estableciera una relación estrecha entre la necesidad del estudio y el aprendizaje de la lengua de Castilla en Europa después de la conquista, como expresión política del expansionismo comercial de España. Sus mejores hombres de letras contribuyeron a la realización de este ideal de intercambio cultural para establecer puentes ideológicos entre diversas formas de ver el mundo.

No son ajenos a estas cuestiones filológicas los dos escritores que hemos presentado en este ensayo, dos extranjeros que se sintieron unidos al destino de un país que los acogió y les permitió desarrollar y consolidar su prestigio como intelectuales, dos epígonos del estudio de la lengua española y su literatura en Estados Unidos. Allí fortalecieron sus nexos con la cultura española y fueron continuadores de su tradición. Para promocionar estos estudios se requería la presencia de expertos como Pedro Henríquez Ureña y Federico de Onís, quienes contribuyeron con su magisterio a la fundación de una manera de pensar el hispanismo -que de alguna manera también fue una posición política- en la compleja, diversa y extraordinaria cultura anglosajona.

Federico de Onís y el poeta Federico García Lorca se encontraron en la Universidad de Columbia entre 1929 y 1930, atraídos por las oportunidades laborales y de estudio que ofrecía el país anglosajón. Intelectuales de otras naciones, como el dominicano Henríquez Ureña, llegaron también con la idea de entrar en contacto con su realidad cultural, y especialmente con su lengua, que estaban deseosos de aprender para interactuar con su vida intelectual y universitaria.
Max Henríquez Ureña escribió en "Hermano y maestro (Recuerdos de infancia y juventud)" una semblanza de su viaje a Nueva York con sus hermanos y su padre, donde entraron en contacto con los rascacielos y la complejidad social de la gran ciudad. Allí surgió en Pedro una ardiente pasión por aprender inglés y de este modo acercarse al vertiginoso ritmo neoyorquino. Señalaba entonces Max: "Nuevas perspectivas se abrían para nosotros en aquella inmensa urbe. Asistíamos constantemente a los mejores espectáculos y conciertos" (1950: 32). También en sus Memorias, Henríquez Ureña reconstruyó una imagen adolescente de la que fuera su primera visión de ese mundo: "Llegamos, por fin a New York, el 30 de Enero; mi primera impresión fue curiosa: había niebla, nevaba terriblemente, y las grandes masas grises de edificios, sobre los cuales se destacaban los enormes edificios de la ciudad baja ofrecían un conjunto enigmático" (1989: 65)

Otros profesores e intelectuales españoles emigraron en diferentes épocas hacia Estados Unidos. Algunos, exiliados por el franquismo, encontraron un lugar como académicos en sus universidades. Entre ellos, se destacaron personalidades como Ángel del Río, Joaquín Casalduero, Jorge Guillén, Américo Castro, Pedro Salinas y Amado Alonso. Esta migración intelectual indudablemente permitió el intercambio cultural entre ambos países. Américo Castro enseñó en la Universidad de Princeton y tuvo como discípulo a Stephen Gilman, estudioso de las obras de Cervantes, Galdós y Manrique; y especialmente reconocido por sus trabajos sobre Fernando de Rojas y La Celestina. Amado Alonso fue profesor e investigador en la Universidad de Harvard. Recordemos que él, Américo Castro, Joaquín Casulduero y Pedro Salinas tuvieron una estrecha relación académica con Ramón Menéndez Pidal en el Centro de Estudios Históricos de Madrid, formando parte de una generación de intelectuales que, como Federico de Onís, recibieron la influencia del medievalista y fundador de la escuela filológica española. 


\section{Palabras finales}

Este ensayo busca, ante todo, explicar cómo Estados Unidos fue decisivo en la formación del pensamiento político, la sensibilidad y la disciplina intelectual del escritor dominicano Pedro Henríquez Ureña, y en la consolidación del trabajo filológico de Federico de Onís, quien impulsó el proceso de expansión de la cultura española a otros dominios espirituales, territorios simbólicos y transoceánicos para favorecer la continuación de las tradiciones hispánicas y facilitar las relaciones triangulares entre España, Hispanoamérica, América y Estados Unidos. Su estancia por varias décadas en la Universidad de Columbia - también fue profesor visitante en las Universidades de Texas y Denver, sin mencionar su paso por la de Puerto Rico-, le permitió reflexionar sobre el hispanismo en un mundo anglosajón ávido de conocimientos por España e Hispanoamérica:

Ha habido siempre en los Estados Unidos cierta gente, poca pero muy selecta, que ha hecho a nuestra España objeto de su amor y su devoción. Aunque la mayoría lo olvidase, siempre había aquí gentes que recordaban que España era el pueblo que descubrió América para el mundo y que españoles fueron los primeros que exploraron la misma tierra de los Estados Unidos, donde aún quedan tantas huellas de nuestra civilización. España era, además, el país romántico por excelencia, cuya tierra, historia y literatura se ofrecían llenas de emoción exótica y legendaria [...]

Entonces empezó a desarrollarse, como una fiebre colectiva, el ansia de conocer el español y todo lo referente a los pueblos donde el español se habla. El español era el instrumento para entenderse con ellos y con ellos comerciar. Pero comerciar, si ha de hacerse bien, es una actividad difícil: no basta con conocer la lengua, hay que conocer a los hombres que la hablan, sus gustos, su carácter, sus costumbres, su psicología, sus ideales; para lograrlo hay que conocer su historia, su geografía, su literatura, su arte. Los pueblos hispanoamericanos son hijos de España: hay, pues, que ir a la fuente y conocer a España. De todo este rodeo es capaz la mente norteamericana cuando quiere orientarse seriamente para la acción, y esta es la razón de su éxito y su eficacia. Ahora tenéis explicado por qué desde 1916 el estudio del español creció en proporciones de cantidad y rapidez que no pueden medirse con las medidas a que estamos habituados en Europa. Las universidades vieron llegar millares de estudiantes a sus clases de español; las escuelas centenares de millares. Y he aquí cómo esta corriente popular, que buscaba el español como un instrumento de comercio y enriquecimiento, vino a encontrarse con aquella otra corriente antigua, selecta y desinteresada, formada por especialistas, escritores y artistas, por estudiosos o enamorados del alma española (Onís, 1920: 14-19).

Las dos estancias de Henríquez Ureña en Estados Unidos contribuyeron a su formación política, que nace de sus preocupaciones por la intervención de este país en la República Dominicana entre 1916 y 1924. Otro momento clave para su formación intelectual fue encontrarse con el rigor de la academia estadounidense, fundamental para el futuro desarrollo de su escritura ensayística. Un signo de la formación y el interés de Henríquez Ureña derivados de su experiencia fue el texto "Veinte años de literatura en los Estados Unidos", incluido en el libro Seis ensayos en busca de nuestra expresión (1928), una crítica y un homenaje a la literatura de un país que conoció muy bien desde sus inicios literarios. El ensayo también aparece en Obra crítica, del FCE de México, en la colección Biblioteca Americana, con un prólogo de Jorge Luis Borges. De esta edición citamos las siguientes reflexiones: 
Durante los veinte años que corren desde 1907 hasta 1927 , la literatura se ha transformado en las dos Américas, la inglesa y la hispánica. La transformación es mayor en los Estados Unidos que en la América española [...]

Al abrirse el nuevo siglo, la literatura en los Estados Unidos padecía estancamiento. Había cien años apenas de obra nacional. Tras los tímidos comienzos — Cooper, Irving, Bryant-, el ciclo heroico cuyo centro fue Concord: Emerson, Hawthorne, Lowell, Holmes, Thoreau, Longfellow, Prescott, y cerca de ellos en zigzags rebeldes, Melville, Poe, Whitman. El espíritu norteamericano halla expresión viva, que Europa acoge como revelación cargada de promesas [...]

Pero en 1900, los grandes nombres, los nombres dominantes, eran los que habían surgido hacia 1870: Howells, James, Bret Harte, Mark Twain. Refiriéndose al país, decía Rodó en Ariel: "Las alas de sus libros hace tiempo que no llegan a la altura en que sería universalmente posible divisarlos" (2001: 309)

Dos escrituras, dos experiencias vitales, dos humanistas recordados con admiración por su intenso y fructífero trabajo intelectual en torno a las relaciones triangulares entre España, Hispanoamérica y Estados Unidos. Con este texto, pretendimos acercarnos a la vida y obra de estos hombres de letras, quienes alguna vez se cruzaron en el Centro de Estudios Históricos de Madrid y hoy constituyen un referente fundamental para comprender la historia de los avatares en busca de nuestra expresión.

\section{REFERENCIAS}

Antelo, Raúl (2009), "La desnudez de espíritu. Henríquez Ureña de-creator", Confluenze: Rivista di Studi Iberoamericani, vol. 1, núm. 1, pp 25-42.

Borges, Jorge Luis (2000), This Craft of Verse, Cambridge, Harvard University Press.

Carrasquilla, Tomás (1952), Obras completas, en Federico de Onís (pról.), Madrid, EPESA.
Castañón, Adolfo (2012), "Pedro Henríquez Ureña. Una pasión sacrificial", Revista de la Universidad de México, núm. 101, pp. 45-48.

Cervantes, Miguel de (1957), El ingenioso hidalgo Don Quijote de la Mancha, en Federico de Onís (ed.), Barcelona, Ediciones Éxito.

Covarrubias Orozco, Sebastián de (1611), Tesoro de la lengua castellana o española, Alicante, Biblioteca Virtual Miguel de Cervantes, disponible en: http://www. cervantesvirtual.com/obra-visor/del-origen-y-principio-de-la-lengua-castellana-o-romance-que-oy-se-vsaen-espana-compuesto-por-el--0/html/00918410-82b211df-acc7-002185ce6064_1180.html

Degiovanni, Fernando (2015), "Una disciplina de guerra: Pedro Henríquez Ureña y el latinoamericanismo", Revista de Crítica Literaria Latinoamericana, año XLI, núm. 82, pp. 135-160.

Díaz Quiñones, Arcadio (2008), "Pedro Henríquez Ureña y las tradiciones intelectuales caribeñas", Letral, núm. 1, pp. 64-80.

Diccionario de Autoridades (2020), "hispanismo", disponible en: http://web.frl.es/DA.html

Guzmán, Martín Luis (1930), The Eagle and the Serpent, en Harriet de Onís (trad.), Nueva York, Alfred A. Knopf.

Henríquez Ureña, Max (sel., pról. y notas) (1950), "Hermano y maestro (Recuerdos de infancia y juventud)", en Pedro Henríquez Ureña, Antología, Ciudad Trujillo, Librería Dominicana.

Henríquez Ureña, Pedro (1905), Ensayos críticos, La Habana, Imprenta Esteban Fernández.

Henríquez Ureña, Pedro (1910), Horas de estudio, París, Sociedad de Ediciones Literarias y Artísticas, Librería Paul Ollendorff.

Henríquez Ureña, Pedro (1916), El nacimiento de Dionisos, Nueva York, Imprenta de Las Novedades.

Henríquez Ureña, Pedro (1918), La versificación irregular en la poesía castellana, tesis doctoral, Universidad de Minnesota, Minnesota, disponible en: https://conservancy.umn.edu/ handle/11299/178050

Henríquez Ureña, Pedro (1922), En la orilla. Mi España, México, Revista México Moderno.

Henríquez Ureña, Pedro (1925), La utopía de América, La Plata, Estudiantina.

Henríquez Ureña, Pedro (1928), Seis ensayos en busca de nuestra expresión, Buenos Aires, Babel.

Henríquez Ureña, Pedro (1940a), Plenitud de España. Estudios de historia de la cultura, Buenos Aires, Losada.

Henríquez Ureña, Pedro (1940b), El español en Santo Domingo, Buenos Aires, Biblioteca de Dialectología Hispanoamericana, Instituto de Filología, UBA.

Henríquez Ureña, Pedro (1945), Literary Currents in Hispanic America, Boston, Harvard University Press.

Henríquez Ureña, Pedro (1947), Historia de la cultura en la América hispánica, México, FCE.

Henríquez Ureña, Pedro (1949), Las corrientes literarias en la América hispánica, México, FCE.

Henríquez Ureña, Pedro (1960), Obra crítica, Jorge Luis Borges (pról.), Emma Susana Speratti Piñero (ed., bibliografía e índice onomástico) México, FCE. 
Henríquez Ureña, Pedro (1975), Desde Washington, La Habana, Casa de las Américas.

Henríquez Ureña, Pedro (1980), Obras completas, en Juan Jacobo de Lara (comp.), Santo Domingo, Universidad Nacional Pedro Henríquez Ureña.

Henríquez Ureña, Pedro (1984), "Flores de otoño”, en Emilio Rodríguez Demorizi (ed.), Pedro Henríquez Ureña. Poesías juveniles, Santo Domingo, Editorial Taller.

Henríquez Ureña, Pedro (1989), Memorias. Diario. Notas de viaje, en Enrique Zuleta Álvarez (Introducción y notas), México, FCE

Henríquez Ureña, Pedro (2004), Desde Washington, en Minerva Salado (Estudio introductorio, compilación y notas), México, FCE.

Henríquez Ureña, Pedro y Jorge Luis Borges (1937), Antología clásica de la literatura argentina, Buenos Aires, Kapelusz.

Maíz, Claudio (2008), "Revisión del mestizaje en la obra de Henríquez Ureña. Armonías selectivas, omisiones y humanismo en una teoría cultural", Alpha, núm. 27, pp.9-28, disponible en: https://scielo.conicyt.cl/scielo.php?script=sci abstract\&pid $=$ S0718-22012008000200002\&lng $=$ pt\& $\bar{n}$ $\mathrm{rm}=$ iso

Mondragón, Rafael (2016), "La memoria como biblioteca. Pedro Henríquez Ureña y la Biblioteca Americana", en Sergio Ugalde Quintana y Ottmar Ette (eds.), Políticas y estrategias de la crítica: ideología, historia y actores de los estudios literarios, Madrid / Frankfurt am Main, Iberoamericana /Vervuert, pp. 191-204.

Nebrija, Antonio de (1992), Gramática castellana, Madrid, Fundación Antonio de Nebrija, disponible en: http://bdhrd.bne.es/viewer.vm?id=0000174208\&page $=1$

Nebrija, Antonio de (1517), Reglas de ortografía en la lengua castellana, Valencia, Benito Monfort, disponible en: https:// books.google.com.co/books?id=8WfD1C2NiBOC\&prints $\mathrm{ec}=$ frontcover\&hl=es\&source=gbs_ge_summary_r\&ca $\mathrm{d}=0 \#_{\mathrm{v}}=$ onepage $\& \mathrm{q} \& \mathrm{f}=$ false

Onís, Federico de (1909), Contribución al estudio del dialecto leonés. Examen filológico de algunos documentos de la Catedral de Salamanca, tesis doctoral, Universidad Central, Madrid, disponible en: https:/gredos.usal.es/handle/10366/142967

Onís, Federico de (1915a), Disciplina y rebeldía, Madrid, Publicaciones de la Residencia de Estudiantes.

Onís, Federico de (1915b), "Sobre la transmisión de la obra literaria de fray Luis de León”, Revista de Filología Española, núm. 2, pp. 217-257.

Onís, Federico de (1920), El español en los Estados Unidos. Discurso leído en la apertura del curso académico de 1920-21, Salamanca, Ediciones de la Universidad de Salamanca, disponible en: https:/gredos.usal. es/bitstream/handle/10366/115705/BG 83232_6. pdf? sequence $=3$ \&isAllowed $=y$

Onís, Federico de (1923), Jacinto Benavente. Estudio literario, Nueva York, Instituto de las Españas.

Onís, Federico de (1924), "El Martín Fierro y la poesía tradicional”, en Homenaje ofrecido a Menéndez Pidal. Miscelánea de estudios lingüísticos, literarios e históricos, Madrid, Hernando, t. II, pp. 403-416.

Onís, Federico de (1931), Canciones españolas (Spanish folk songs), Nueva York, Instituto de las Españas.
Onís, Federico de (1932), Ensayos sobre el sentido de la cultura española, Madrid, Publicaciones de la Residencia de estudiantes.

Onís, Federico de (1934), Antología de la poesía española e hispanoamericana (1882-1932), Madrid, Centro de Estudios Históricos.

Unamuno, Miguel de (1953), Cancionero. Diario poético, en Federico de Onís (ed. y pról.), Buenos Aires, Losada.

Onís, Federico de (1955), "Sobre el concepto del modernismo", en España en América. Estudios, ensayos y discursos sobre temas españoles e hispanoamericanos, Puerto Rico, Ediciones de la Universidad de Puerto Rico.

Onís, Federico de (Introducción y notas) (1956), Anthologie de la poesie latino-amiricaine, París, UNESCO, Les Editions Nagel.

Onís, Federico de (ed.) (1959), Luis Palés Matos (1898-1959), Santa Clara, Cuba, Universidad Central de las Villas, Instituto de Estudios Hispánicos.

Onís, Federico de (1961), Antología de la poesía española e hispanoamericana (1882-1932), Nueva York, Las Américas Publishing Company.

Real Academia Española (RAE) (2020), "hispanismo", disponible en: https://dle.rae.es/hispanismo? $\mathrm{m}=$ form

Diccionario de Autoridades (2020), "hispanismo", disponible en: http://web.frl.es/DA.html

Reyes, Alfonso y Pedro Henríquez Ureña (1986), Correspondencia 1907-1914, México, FCE.

Roggiano, Alfredo (1961), Pedro Henríquez Ureña en los Estados Unidos, Iowa, State University of Iowa.

Roggiano, Alfredo (1989), Pedro Henríquez Ureña en México, México, UNAM.

Valdés, Juan de (1736), Diálogo de la lengua, Madrid, Biblioteca Digital Hispánica, disponible en: http://bdh.bne.es/bnesearch/detalle/bdh0000048928

Valdez, Juan (2008), Language, Race, and Identity in Pedro Henriquez Ureña's Dominican Oeuure: A Study on Language Ideologies, tesis doctoral, The City University of New York, Nueva York.

Valdez, Juan (2010), Tracing dominican identifiy. The writings of Pedro Henríquez Ureña, Nueva York, Palgrave Macmillan.

Valdez, Juan (2015), En busca de la identidad: la obra de Pedro Henríquez Ureña, Buenos Aires, Katatay.

Valerio-Holguín, Fernando (2011), "Pedro Henríquez Ureña: Utopía del silencio”, Caribbean Studies, vol. 39, núm. 1/2, pp. 195-221.

Weinberg, Liliana (2014), Biblioteca Americana. Una poética de la cultura y una política de la lectura, México, FCE.

William Marín Osorio. Profesor e investigador adscrito a la Universidad Tecnológica de Pereira, Colombia y a la Universidad Libre Seccional Pereira, Colombia. Doctor en Letras por la Universidad de Buenos Aires, Argentina, y en Literatura por la Universidad Tecnológica de Pererira, Colombia; Magíster en Literatura Hispanoamericana por el Instituto Caro y Cuervo, Colombia. Especialista en Docencia en Historia y Cultura en América Latina por la Universidad Pablo de Olavide, España. Ganador de diversos certámenes de novela y poesía. Director del Grupo de Investigación Crítica y Creación. Ha publicado libros de ensayo, novela, cuento y poesía. Sus artículos han aparecido en revistas especializadas nacionales e internacionales. 